\title{
La Michoacana: la extraordinaria historia de un éxito empresarial en Tocumbo
}

\author{
Patricia Arias
}

MARTÍN GONZÁLEZ DE LA VARA, 2006

\section{La Michoacana. Historia de los paleteros de Tocumbo}

El Colegio de Michoacán, Gobierno del Estado de Michoacán, Zamora, Michoacán, 237 pp., incluye fotografías e ilustraciones.

$\mathrm{M}$ artín González, el autor de este flamante libro -medio en broma, medio en serio- dice que una de las razones para leerlo tiene que ver con una pregunta que alguna vez todos nos hemos hecho: ¿Por qué hay tantas paleterías La Michoacana en casi cada rincón de México? Una parte de la respuesta se encuentra - como bien lo demuestra el libro- en los espacios urbanos o, de manera más precisa, en la ciudad de México, donde empezó a escribirse, décadas atrás, esa parte tan identificable de la paletería mexicana. Otra pregunta forzosa de los que conocen esa porción de Michoacán es: ¿̨por qué Tocumbo, pueblo de origen de los paleteros michoacanos, de no más de 2500 habitantes, resulta ser un espacio rural próspero y bien conservado a diferencia de la imagen de deterioro, empo-

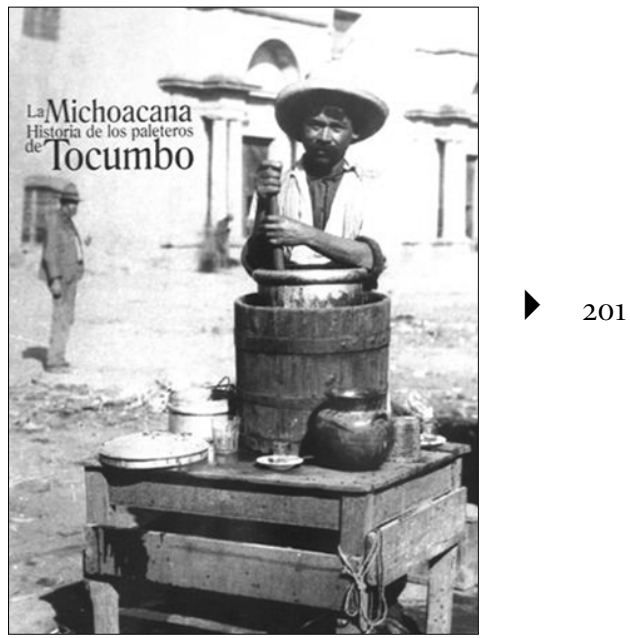

brecimiento y abandono de tantas comunidades rurales en México hoy en día? ¿Cuántas comunidades rurales pueden presumir de una serie de monumentos a hitos locales - como el de la paleta o el de uno de los pioneros de la paletería - y obras - el hermoso parque El Ojo de Agua, un nuevo cementerio, un amplio boulevard, el moderno templo del Sagrado Corazón diseñado por el arquitecto Pedro Ramírez Vázquez, calles bien pavimentadas e iluminadas-? Esa parte

\footnotetext{
La Michoacana: An Extraordinary Story of Entrepreneurial Success in Tocumbo

PATRICIA ARIAS: Universidad de Guadalajara, Guadalajara, México. $<$ parias@megared.net.mx $>$

Las fotografías reproducidas en este texto pertenecen al libro reseñado. $\dot{2}$ Desacatos, núm. 27, mayo-agosto 2008, pp. 201-206.
} 
de la respuesta hay que encontrarla, como nos enseña también esta obra, en la manera como los paleteros han redefinido, rediseñado y resignificado sus relaciones con su comunidad de origen.

A fin de cuentas, se puede decir que en este libro Martín González de la Vara nos cuenta una historia peculiar en la que resulta evidente que las relaciones entre el campo y la ciudad estuvieron siempre mucho más entreveradas de lo que el viejo supuesto de una dicotomía funcional rural-urbano impuso durante mucho tiempo en las ciencias sociales.

La manera escogida para contar esta historia es también original. Desde 1991 y de manera casi ininterrumpida, El Colegio de Michoacán ha confeccionado los libros de gran formato, ilustrados e ilustrativos, que cada año ofrece como regalo el gobierno del estado de Michoacán. Los temas tratados han sido muy variados, pero este trabajo, que correspondió al año 2006, representa el primer acercamiento a una microregión de Michoacán, centrado y referido a un asunto particular: la trayectoria de una actividad económica que ha sido detonador de una modalidad muy singular de desarrollo local: la manufactura urbana de paletas que logra impactar y rediseñar la dinámica socioeconómica de la comunidad rural de Tocumbo y su región.

La historia, por el carácter de la colección y el perfil de sus destinatarios, está contada en clave de divulgación, es decir, de manera tal que cualquier lector puede entenderla y también disfrutarla, ya que se encuentra profusa- mente ilustrada con mapas y fotografías históricas que proceden de la Fototeca Nacional del Instituto Nacional de Antropología e Historia (INAH) y de la Fototeca de El Colegio de Michoacán, así como fotografías tomadas especialmente para el libro por José Ignacio González Manterola, Guadalupe Lemus, Alejandro Maass y Fernán González de la Vara. Las imágenes y los pies de fotos pueden bastar para conocer la obra, pero también sirven de señuelo para interesarse por conocer el resto del trabajo.

Aunque en clave de divulgación, la investigación que sustenta este libro es sin duda profesional. Ésta es la parte menos explicitada en la obra, pero no cabe duda de que Martín González de la Vara dedicó buena parte del año 2006 a preparar y redactar este libro: revisión de bibliografía y cartografía sobre la región y el tema, así como realización de entrevistas en Tocumbo y Zamora. Al mismo tiempo, en el trabajo se reconoce un viejo interés del autor en torno a temas relacionados con la historia de la comida en México. En 1989 publicó el libro Historia del helado en México (Maass y Asociados, México, 1989) y ha elaborado otros libros y artículos de asunto gastronómico.

Este libro sobre los paleteros de Tocumbo es no sólo una parte de la historia de la heladería sino, sobre todo, en palabras del autor, "una de las más extraordinarias historias de éxito empresarial que han existido en México". Martín aclara desde el principio que las más notables zonas paleteras de México son dos: Mexticacán, en la parte norte de la región de los Altos de
Jalisco, y Tocumbo, en el occidente de Michoacán y una parte del suroriente de Jalisco, aunque su trabajo se refiere, por razones obvias, exclusivamente al ejemplo michoacano.

El texto, de 197 páginas, está organizado en tres grandes apartados o capítulos: la ubicación histórico-geográfica de la región paletera de $\mathrm{Mi}$ choacán; una revisión histórica de larga duración de la historia del helado y otros alimentos congelados en México; y la historia, trayectoria, vicisitudes y desafíos de la heladería en Tocumbo vista a través de "un grupo muy notable de empresarios oriundos de dicha área”.

En la primera parte, llamada "Historia de la región paletera de Michoacán", el objetivo ha sido describir el paisaje en términos geográficos e históricos. La tarea no ha sido fácil, ni siquiera para un historiador como Martín, porque en verdad no se trata de una región natural ni corresponde a una jurisdicción administrativa específica y delimitada. Así, el autor reconstruye la trayectoria del poblamiento en la intersección entre la Sierra Madre del Sur y el Eje Neovolcánico que hoy constituye la región paletera: la franja limítrofe entre Michoacán y Jalisco que, a partir de Tocumbo, se extiende por rancherías, pequeñas comunidades, pueblos nuevos, antiguas haciendas, hasta Cotija, Los Reyes y Tinguindín, y por la vertiente jalisciense hasta Quitupan. En ese espacio "se originaron núcleos o redes específicas de fabricantes de paletas y helados"; es decir, se trata de un espacio atravesado y delimitado por redes sociales muy especializadas, 


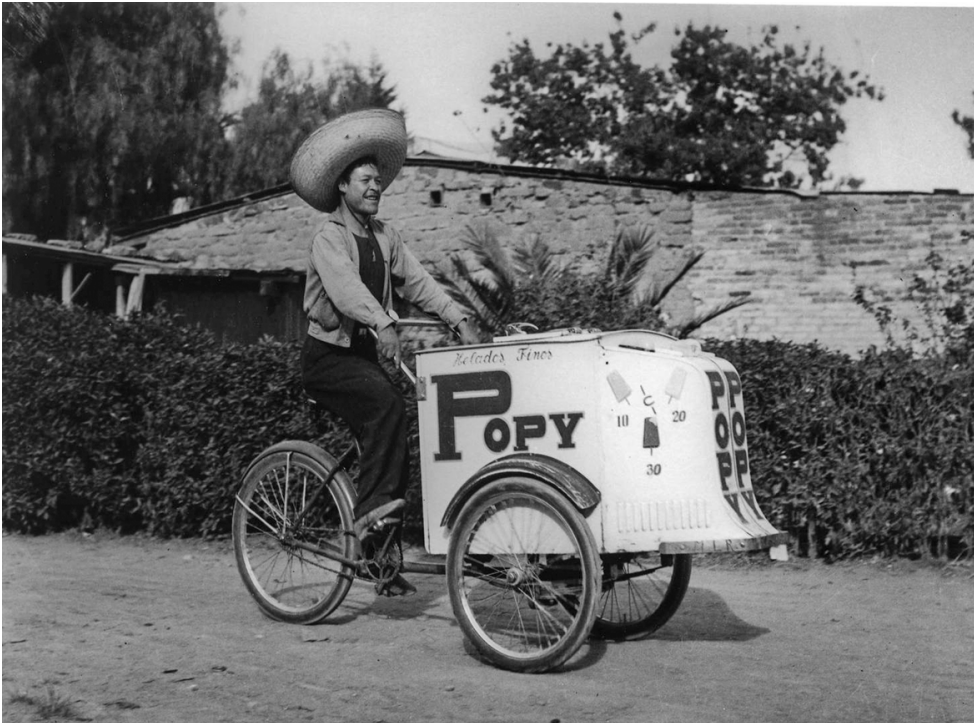

creadas y articuladas a partir de una actividad económica que, por eso mismo, cruza fronteras geográficas, económicas, políticas. Alrededor de la paletería y su sede tocumbense "se han relacionado varias poblaciones que pertenecen a jurisdicciones y ámbitos económicos muy distintos".

Aunque el proceso de articulación a través de la paletería es relativamente reciente, lo que parece común al espacio paletero es que la mayoría de las poblaciones que lo integran corresponden al mundo ranchero, es decir, a esa franja de sociedades rurales mestizas, donde un principio básico de organización ha sido la autonomía, y en la que el Estado ha tenido, en comparación con otras sociedades rurales, escasa influencia en la arquitectura social local ${ }^{1}$. Ese ha sido el trasfondo cultural, señala el autor, que les ha

\footnotetext{
2 Luis González, “Gente de campo", Vuelta, núm. 151, junio, 1989, pp. 22-29.
}

permitido a los paleteros "construir sus acuerdos y su organización productiva informal" (p. 15). Hay que recordar que, de acuerdo con don Luis González, la matriz sociocultural ranchera se articula en torno a tres elementos centrales: un fuerte sentido individualista de la propiedad asociado a una fuerte, difundida $y$ bien valorada tradición de trabajo personal y una lealtad a ultranza del ranchero con su familia, tanto en su versión nuclear como extensa (ibid.). Todos estos elementos aparecen en la manera cómo se ha organizado, desde sus orígenes, la paletería en Tocumbo, desarrollada — destaca Martín — a partir de "una red de pequeños empresarios que se agrupan por vínculos familiares, comunales y de parentesco" ( $\mathrm{p}$. 14). En términos económicos destacan, como en otras sociedades rancheras, además de la agricultura, la actividad ganadera en las tierras altas y una fuerte tradición comercial.
Como bien sintetiza el autor, se trata de una región que ha sido articulada "más a partir de la emigración que del poblamiento" (p. 22). Porque en el caso de Tocumbo fue una actividad exitosamente desarrollada fuera de la comunidad la que redefinió el espacio rural regional: el dinamismo de la paletería permitió integrar cada vez más familias y poblaciones a esa actividad en las ciudades. La paletería, además, surgió a partir de iniciativas, recursos y capitales pequeños, en los que el Estado tuvo y ha tenido escasa intervención.

Para el siglo XX el texto da cuenta de los sucesivos factores, sobre todo políticos - hay que recordar que se trata del Estado cardenista por excelencia-, que fueron definiendo, con sus oportunidades y limitaciones, el horizonte regional: reforma agraria, obras públicas de variada índole, nuevas posibilidades de desarrollo agrícola. Y sin embargo, a partir de la década de 1940 los tocumbenses comenzaron a salir hacia Estados Unidos y hacia diferentes ciudades del país. Esto significa que, a diferencia de lo sucedido en otros espacios rurales, donde el reparto agrario y los apoyos al campo supusieron un proceso, aunque fuera temporal, de recampesinización, en Tocumbo no parecen haber sido suficientes para retener a la población, cuestión que Martín atribuye sobre todo al crecimiento demográfico.

Sin duda, en el caso de Tocumbo llama mucho la atención la búsqueda tan temprana, por parte de actores locales, de opciones económicas y laborales diferentes a las agropecuarias. Como es sabido, ese fue un fenómeno 
mucho más característico y generalizado en el México rural desde la década de 1970 cuando, vinculadas a la última fase del proceso de sustitución de importaciones, se echaron a andar, en diferentes sociedades rurales, diversas y novedosas actividades manufactureras y pecuarias que procuraban mitigar la crisis inacabable de las actividades agropecuarias tradicionales.

El caso de Tocumbo llama también la atención por ser un ejemplo pionero, exitoso y prolongado de búsqueda de opciones económicas fuera de la comunidad, pero anclado en los vínculos sociales y los recursos culturales locales, lo que lo hace un caso muy especial, muy peculiar y casi único de desarrollo local. No sólo eso. Al mismo tiempo, hay que reconocer que el de los tocumbeños es uno de los esca-

sos ejemplos colectivos, comunitarios si se quiere, más exitoso de migración interna. La bibliografía ha documentado la inserción de los y las migrantes rurales en las ciudades, pero sobre todo en las actividades y empleos peor pagados de las economías urbanas o, de manera más reciente, las historias de éxito de algunos grupos de migrantes en Estados Unidos, pero conocemos muy poco, casi nada, de las experiencias colectivas exitosas de la gente del campo que se ha ido a las ciudades. En ese sentido, la experiencia de las paleterías La Michoacana representa un modelo, en tres sentidos a lo menos: como experiencia peculiar de migración interna, de inserción laboral urbana y de organización del trabajo individual y colectivo.

En la segunda parte del libro, llamada "Historia del helado y otros ali- mentos congelados", el autor nos ofrece una perspectiva de muy larga duración en torno al tema, desde sus orígenes más remotos, quizá en China; su llegada y difusión en Europa, hasta su aterrizaje y domesticación, allá por el siglo XVII, en tierras novohispanas. Allí, el lector encontrará un bosquejo histórico culto y muy bien ilustrado, que va desde la organización del estanco de la nieve, las vicisitudes para conseguir y conservar el hielo, las técnicas y el consumo doméstico de postres congelados, hasta su transformación, durante el siglo XIX, en un producto económicamente más accesible y geográficamente mucho más difundido, que dio lugar al muy retratado nevero callejero. El repaso tendrá sin duda gran acogida y será de gran provecho entre los lectores no especializados porque sintetiza y traza de manera ejemplar una historia no sólo muy larga sino además con muchos vericuetos, que el autor ha logrado descifrar y presentar de manera tan comprensible como amena, apoyado en una estupenda selección gráfica.

La parte final del capítulo ofrece un recorrido que es poco usual en los libros de difusión y que vale la pena valorar: las iniciativas — exitosas y frustradas- de las múltiples heladerías y fábricas de helados que surgieron no sólo en la ciudad de México sino en diferentes ciudades del país a lo largo del siglo XX. El recorrido incluye desde las heladerías de postín hasta los proyectos populares de venta en carritos y las nieves de garrafa que, aunque en pocos mercados y ligados a consumos muy particulares, han logrado sobrevivir en toda la geografía nacional.
El capítulo concluye con un apartado necesario y un subtítulo acertado: "Los enigmas de la globalización". Allí, Martín da cuenta de la feroz competencia que se ha desatado en los últimos años en la industria del helado, en la que las batallas se libran en muchos frentes, cada vez más costosos, como la mercadotecnia y la variedad para atender diferentes segmentos del mercado. Sin duda, no la tiene fácil el grupo de paleteros michoacanos. Con todo, señala el autor, la actividad "se ha seguido expandiendo y se ha creado una imagen comercial muy reconocida por el público".

La tercera parte del libro - "Los paleteros de Tocumbo"- es, por supuesto, el capítulo medular del trabajo. Martín da cuenta de la existencia, hasta 1940, de la serie de actividades que realizaba la gente de Tocumbo para sobrevivir: habían sido dotados de tierra, lo que les permitía desarrollar una agricultura que nunca pasó de ser más o menos pobre, conseguían dinero en efectivo trabajando como jornaleros en los campos de caña, tenían algo de ganado, se iban a trabajar a Estados Unidos de manera temporal, las mujeres elaboraban gabanes y sombreros con palma del cerro que se vendían allí mismo. Nada muy distinto de lo que sucedía en un sinfín de pueblos. En cualquier caso, la semblanza de los primeros años de los dos pioneros - los primos Agustín Andrade e Ignacio Alcázar - sugiere que ambos no tenían acceso a la tierra y más bien fueron aprendices de muchos oficios.

La clave parece estar en la ciudad. Los pioneros migraron a la ciudad de México a principios de la década de 
1940, en los años de la Segunda Guerra Mundial, tiempo de bonanza para México, cuando la capital del país comenzaba a crecer y atraía población. Lo curioso es que, como bien se señaló en el capítulo anterior, en ese tiempo comenzó a desarrollarse también la fabricación industrial de helados, cuando "se fundaron casi todas las primeras compañías importantes de helados". En ese contexto de competencia, el mérito de los tocumbeños para insertarse y multiplicarse en ese nicho resulta aún más destacable.

¿Cómo fue posible? Martín apunta sobre todo al crecimiento demográfico urbano, pero da indicios para pensar que los paleteros tocumbeños pudieron aprovechar la emergencia de una nueva segmentación social del mercado y las paleterías de los de Tocumbo se orientaron a satisfacer el gusto de los sectores más populares del mercado urbano y siguieron, con mayor eficacia que las paleterías formales, los desplazamientos de la población urbana. Porque además, gracias al trabajo personal y arduo de los pioneros en sus primeras paleterías, desde fines de la década de 1940 pudieron empezar a abrir más paleterías en diferentes rumbos de la ciudad de México para lo cual reclutaban trabajadores entre sus paisanos y parientes de Tocumbo. Poco a poco, dice el autor, "la costumbre de traspasar o dejar encargadas las paleterías a hijos o parientes se convirtió en toda una tradición dentro de la naciente red de paleteros de Tocumbo". El proceso de emergencia y reproducción de las paleterías narrado en el capítulo 3 da para todo un estudio de caso en escuelas de negocios.

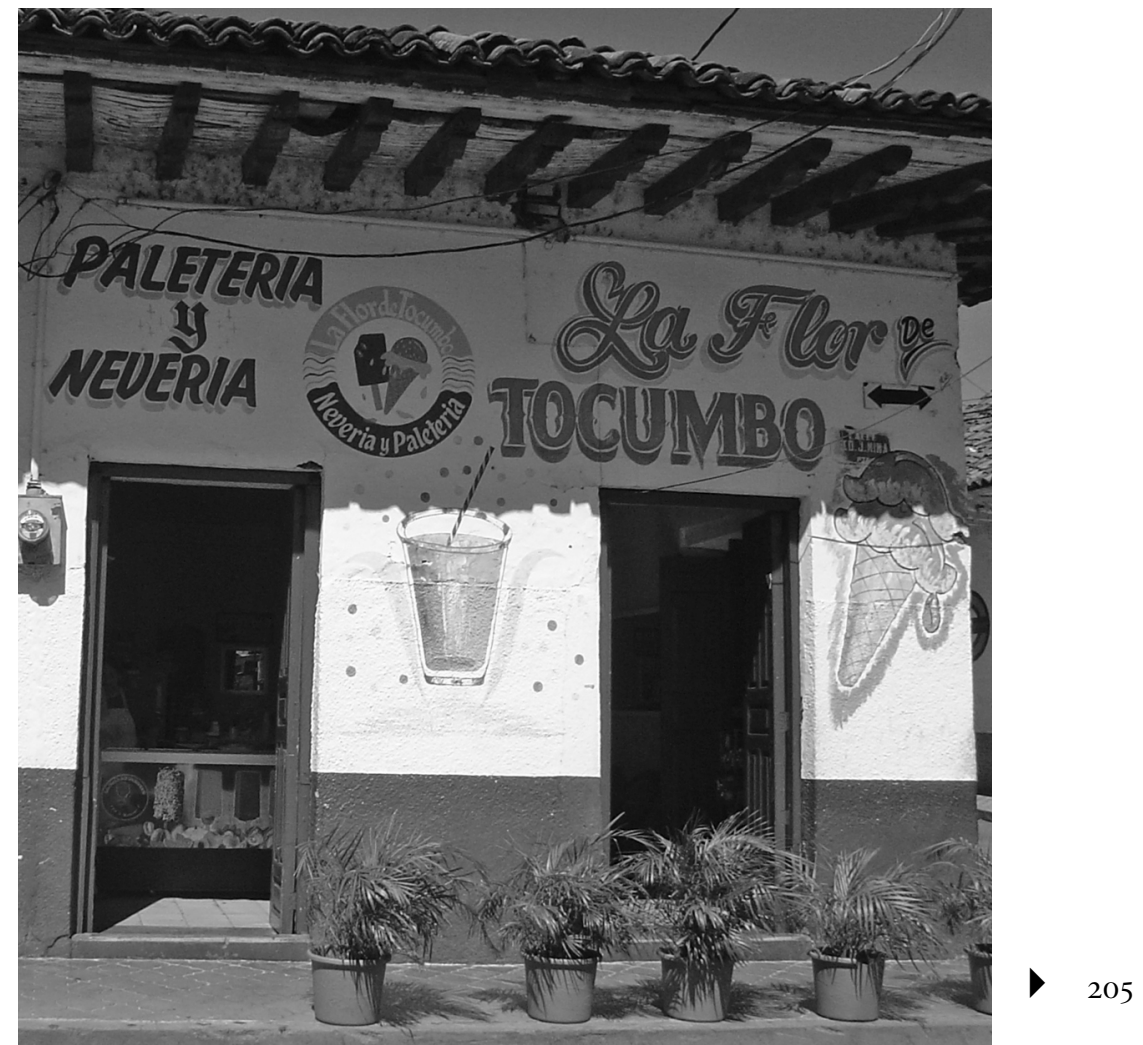

Pero desde un punto de vista sociológico Martín llama la atención sobre tres puntos centrales: la importancia del crédito y la confianza para la viabilidad, reproducción y crecimiento de los negocios que, como las paleterías, emergen de iniciativas y con recursos de muy pequeña escala. El ejemplo de los paleteros de Tocumbo muestra lo poco, muy poco, que se necesita para echar a andar una actividad, para que la gente pueda potenciar su capacidad y disponibilidad para el trabajo y estimular la emergencia de nuevas habilidades. El acceso al crédito, en cantidades en verdad muy pequeñas, pero otorgado de manera precisa, rápida y eficiente, fue lo que resultó clave para el desenvolvimiento de una actividad económica exitosa, multiplicadora y perdurable. Desde luego que los pioneros, que se hicieron cargo de la tarea de financiar a los que de manera sucesiva llegaban a la ciudad para incorporarse a la actividad paletera, no cobraban poco, pero eso mismo da cuenta de la potencialidad del crédito cuando éste es oportuno y se dirige de manera eficaz a una actividad efectivamente viable. Las relaciones de confianza mutua entre los pioneros y los aspirantes a paleteros garantizaban el crédito, el pago y, no menos importante, reiteraban la certeza que avalaba empresas futuras.

El crédito, o si se quiere, las enor- 
mes dificultades y complicaciones para obtenerlo en México, es un asunto que las ciencias sociales han mencionado una y otra vez y que, sin embargo, sigue siendo el talón de Aquiles para el desenvolvimiento de las actividades de pequeña escala en el país. En el asunto del crédito se manifiesta, desde hace décadas, el desencuentro entre las necesidades y demandas de los sectores y agentes locales y las políticas públicas.

El otro elemento que muy bien destaca Martín es la flexibilidad de la actividad paletera, en la que cada propietario de un establecimiento ha podido, gracias a su contacto directo con el público, desplegar estrategias particulares y focalizadas de acuerdo con los lugares y productos donde se encuentran, con los gustos de sus clientelas particulares, con las temporadas que define el paso de las estaciones. Esto les ha permitido, además, reunirse cada año, en diciembre (cuando las ventas de productos helados bajan) en Tocumbo a celebrar la Feria de la Paleta. Las experiencias exitosas suelen cundir como la humedad y son rápidamente incorporadas a las estrategias y productos de Las Michoacanas. La flexibilidad, como sabemos, es algo que se le dificulta a la gran empresa - desde la añosa Mc Donald's hasta la flamante Starbuck's - que tiende, de manera irremediable, a la homogeneización y la estandarización.

Así las cosas, a fines de la década de 1950 “ya existía una próspera red de empresarios paleteros oriundos del occidente de Michoacán que operaba en la ciudad de México". En la década de 1960 se calculaba que había ya cerca de quinientas paleterías en la capital del país. Las paletas de Michoacán, distribuidas por todos los rincones de la ciudad, más tarde del país, se lograron "posicionar" muy bien en el gusto del público popular: un refrigerio con mucha, mucha fruta muy dulce y colorida, de múltiples sabores.

El impacto de la paletería en Tocumbo y su región ha sido impresionante: los propietarios de establecimientos han comprado ranchos ganaderos y huertas de aguacate, pero en verdad "de descanso"; han construido casas suntuosas; han financiado un sinfín de obras públicas; han hecho famosa la Feria de la Paleta que se celebra en Tocumbo desde 1987, lo que les permite regresar a pasar las vacaciones en Tocumbo y renovar sus relaciones y redes de amistad y trabajo.

No sólo eso. Con el correr de los años, muchos han establecido industrias ligadas a la paletería en el propio Tocumbo: fábricas de bases lácteas para helado, de filtros y equipo de refrigeración que impactan positivamente en el empleo local y reproducen el aprendizaje industrial y comercial de la fabricación de helados. Pero en general, más allá de la paletería parecería que no hay opciones de inversión local. Las obras apuntan, como en tantas partes, a un proceso de terciarización del campo, es decir, a una asociación cada vez mayor del mundo rural con el descanso, el paseo, el festejo y menos con actividades agropecuarias.

¿Hasta dónde, hasta cuándo es posible seguir creciendo? Martín da cuenta de los aciertos, aprendizajes, recursos, habilidades con que cuentan los paleteros de hoy, pero también de los límites a su proliferación, sobre todo cuando el crecimiento demográfico es escaso y el crecimiento económico está estancado.

Pero de lo que parece no caber la menor duda es que si hubiera habido más ejemplos como el de Tocumbo habría habido quizá menos migración, seguramente menos opciones ilegales y peligrosas en el campo mexicano ( $\vdots 0$ alguien cree que es el gusto por las emociones fuertes lo que fomenta la producción de enervantes?), menos operativos militares en Michoacán.

El futuro, como siempre, queda abierto y así lo ha dejado el autor: con certezas e interrogantes. Pero también de otra cosa no cabe la menor duda: trabajos como el de Martín son fundamentales para rescatar y aprender de las iniciativas de diversificación económica que promovieron, con gran esfuerzo, las sociedades rurales en México, muchas de las cuales fueron arrasadas por la ola de reformas neoliberales y el Tratado de Libre Comercio (TLC). El ejemplo de Tocumbo afortunadamente persiste y ha disfrutado, además, de la mirada acuciosa y sensible de estudiosos como Martín González de la Vara, que nos han permitido conocerlo.

La Michoacana. Historia de los paleteros de Tocumbo obtuvo el Premio de Difusión 2007 del Instituto Nacional de Antropología e Historia (INAH).

enero 2007 